\title{
SISTEM PAKAR PENENTU KOPI TERBAIK BERDASARKAN BARISTA PADA KOLARIS KOPI
}

\author{
Reggy Saputra \\ Program Studi Teknik Informatika, Fakultas Teknik dan Ilmu Komputer, \\ Universitas Indraprasta PGRI \\ Jalan Raya Tengah No 80, Kelurahan Gedong, Pasar Rebo, Jakarta Timur \\ Reggysaputra123@gmail.com
}

\begin{abstract}
Abstrak
Sistem pakar dibuat untuk mempermudah user atau pengguna komputer, agar mampu memahami berbagai macam hal yang ingin diketahui dan dikembangkan dengan cara mengadopsi pola pikir dan pengetahuan manusia (yang dalam hal ini adalah seorang expert atau pakar), yang ditujukan untuk mencari sebuah atau beberapa buah solusi yang memuaskan usernya seperti ketika seorang pakar atau ahli. Café kolaris kopi ini melakukan kegiatan menentukan menu kopi terbaik berdasarkan barista dan pencataan penjualan menggunakan kwitansi, sehingga pencatatan dilakukan secara manual dan belum melibatkan alat bantu komputer. Berdasarkan permasalahan tersebut, maka perlu dirancang sistem penentu kopi yang sesuai keinginan konsumen. Tujuan dari penelitian ini adalah menganalisa sistem yang sedang berjalan pada café kolaris kopi dan menerapkan metode fuzzy logic pada penentu pemilihan kopi yang tepat. Pada penelitian ini, metode yang digunakan metode grounded teory dan fuzzy logic untuk sistem pengembangannya. Sedangkan dalam pengumpulan data penelitian, dilakukan observasi langsung ke café, wawancara kepada pihak terkait dicafe dan studi literature. Hasil dari penelitian ini diperoleh bahwa dengan diterapkan aplikasi sistem penentu kopi terbaik pada café kolaris kopi ini, konsumen akan lebih mudah menemukan kopi apa yang tepat dan sesuai selera.
\end{abstract}

Kata Kunci : sistem pakar, penentu kopi, java, php

\begin{abstract}
The expert system is made to facilitate user or computer users, in order to be able to understand the various things that want to be known and developed by adopting the mindset and human knowledge (which in this case is an expert or an expert), aimed at finding a or some solution that satisfies the user such as when an expert or expert. Café Kolaris Coffee is doing the best coffee menu based on the barista and sales pencatation using receipts, so that the recording is done manually and does not involve computer tools. Based on the problem, it is necessary to be designed coffee determinant system as consumers desire. The purpose of this research is to analyze the running system in the Coffee Kolaris café and apply the fuzzy logic method to the appropriate selection of coffee determinants. In this study, the methods used grounded teory and fuzzy logic methods for its development system. While in the collection of research data, there is direct observation to the cafe, interviews to the parties related to dicafe and literature study. The result of this research was obtained that by applying the best coffee determinant system application at Café Kolaris This coffee, consumers will be more easily find what coffee is right and according to taste.
\end{abstract}

Keyword : Good Data Management Application, java, Research and Development Method.

\section{PENDAHULUAN}

Sistem pakar dibuat untuk mempermudah user atau pengguna komputer, agar mampu memahami berbagai macam hal yang ingin diketahui dan dikembangkan dengan cara mengadopsi pola pikir dan pengetahuan manusia (yang dalam hal ini adalah seorang expert atau pakar). Salah satu usaha yang dapat menggunakan komputer sabagai alat bantu bisnis adalah usaha café Kolaris Kopi. Café Kolaris kopi merupakan salah satu café kopi yang berlokasi di bekasi. Café ini melakukan kegiatan menentukan menu kopi terbaik berdasarkan barista dan pencataan penjualan menggunakan kwitansi, sehingga pencatatan dilakukan secara manual dan belum melibatkan alat bantu komputer. Pencatatan yang dilakukan secara manual akan membutuhkan banyak waktu dibandingkan dengan pencatatan yang dilakukan dengan komputer. Kopi merupakan minuman yang banyak digemari oleh masyarakat dunia, termasuk juga di Indonesia. Indonesia menghasilkan kopi robusta lebih 
tinggi yaitu sebesar $93 \%$ dibandingkan kopi arabika. Berdasarkan informasi yang didapat dari ICO Coffee Statistics dan Asosiasi Eksportir Kopi Indonesia (AEKI) [1]. Logika fuzzy pertama kali diperkenalkan oleh Jan Lukasiewicz pada tahun 1930, serta pertama kali dipromosikan oleh Lotfi Zadeh pada tahun 1962 melalui jurnal "Fuzzy set". Inferensi fuzzy Mamdani merupakan kerangka kerja linguistik, dengan inferensi fuzzy ini proses berfikir manusia dapat dimodelkan. Inferensi fuzzy Mamdani telah digunakan secara luas untuk menangkap pengetahuan para pakar, sehingga memungkinkan penggunaan inferensi fuzzy Mamdani untuk menggambarkan keahlian pakar secara lebih intuitif, yang lebih mirip pakar dalam mengambil keputusan [2]. Sistem Pakar adalah sebuah program komputer yang mencoba meniru atau mensimulasikanpengetahuan (knowledge) dan keterampilan (skill) dari seorang pakar pada area tertentu. Selanjutnya sistem ini akan mencoba memecahkan suatu permasalahan sesuai dengan kepakarannya [3]. Berdasarkan masalah yang timbul penulis ingin menganalisa merancang, dan membuat sistem pakar penentu kopi terbaik berbasis komputerisasi, yang diharapkan dapat membantu permasalahan-permasalahan pada sistem café yang sudah ada. Oleh karena itu, dengan melalui skripsi yang berjudul"'Sistem Pakar Penentu Menu Kopi Terbaik Berdasarkan Barista", yang nantinya dapat menentukan menu kopi terbaik sekaligus memberikan solusi berdasarkan rule yang ada.

\section{PENELITIAN RELEVAN}

Beberapa penelitian relevan yang digunakan sebagai acuan pada penelitian ini adalah sebafai berikut :

Penelitian oleh [4], dengan judul Sistem Pakar Fuzzy Penentuan Kualitas Kakao. Tujuan penelitian ini adalah menghasilkan sistem pakar fuzzy yang dapat digunakan dalam proses menentukan kualitas kakao.

Penelitian selanjutnya, oleh [5] dengan judul Penerapan Fuzzy Logic Dengan Menggunakan Metode Mamdani Untuk Memprediksi Kualitas Kopi. Tujuan untuk memprediksi kualitas kopi sebagai upaya mengurangi kendala yang terjadi pada tenaga manusia yang berbasis logika fuzzy.

Persamaan dari penelitian sebelumnya dengan penelitian ini adalah sama-sama menerapkan fuzzy logic untuk membantu dalam proses penentuan.

\section{METODE PENELITIAN}

Metode penelitian yang digunakan peneliti adalah metode grounded (grounded research) dan fuzzy logic untuk sistem pengembangannya. Menurut [6], "metode grounded (grounded research) yaitu suatu metode penelitian berdasarkan pada fakta dan menggunakan analisis perbandingan dengan tujuan mengadakan generalisasi empiris, menetapkan konsep, membuktikan teori, mengembangkan teori, pengumpulan dan analisis data dalam waktu yang bersamaan. Dalam riset ini data merupakan sumber teori atau teori berdasarkan data".

1. Observasi (pengamatan)

Merupakan metode yang dilakukan oleh penulis secara langsung ke lapangan untuk memperoleh sumber data yang sesuai dengan kebutuhan [7]. Penulis terjun langsung kelapangan untuk melakukan pengamatan dan meneliti secara cermat dan sistematik.

Peneliti dilakukan pada bulan juni 2020 di café kolaris kopi.

2. Wawancara

Dalam melakukan wawancara ini, peneliti melakukan tanya jawab kepada pihak yang terkait [8], yaitu kepada pemilik café kolaris kopi dengan mengajukan beberapa pertanyaan yang ada kaitannya dengan kebutuhan data yang dikumpulkan peneliti.

3. Dokumentasi

Penulis melakukan pengumpulan data dengan cara mencatat semua data yang ada pada dokumen atau arsip dibagian pendataan [9], pada cafe kolaris kopi. 


\section{HASIL DAN PEMBAHASAN}

\section{Analisa Permasalahan}

Berdasarkan analisis proses yang dilakukan oleh penulis pada café kolaris kopi terdapat beberapa permasalahan sebagai berikut :

1. Belum adanya penentu selera kopi untuk konsumen berbasis komputerisasi.

2. Penyimpanan data yang belum efektif karena belum adanya database berbasis komputerisasi dan masih berbentuk kertas.

3. Penyimpanan data yang kurang baik, sehingga terjadi kesulitan apabila menginginkan pencarian data kembali, dikarenakan masih bersifat manual.

4. Pembuatan laporan pembelian penjualan dan pemasok kepada pemilik café sering terlambat, sehingga terjadi kesalahan dalam pembuatan laporan.

\section{Alternatif Penyelesaian Masalah}

Penyelesaian masalah yang diharapkan pada café kolaris kopi lebih mendasar dan terletak pada sistem yang dijalankan di café, sehingga perlu adanya penyelesaian masalah yang tepat, serta mengambil langkah-langkah sesuai dengan yang diharapkan pemilik café agar kedepannya café kolaris kopi semakin maju. Adapun penyelesaian masalah tersebut :

1. Merancang sistem aplikasi penentu selera kopi untuk konsumen berbasis komputerisasi.

2. Membuat database penyimpanan data yang sistematis agar penyimpanan data lebih efektif

3. Membuat database yang sistematis sehingga memudahkan dalam pencarian data yang dibutuhkan dalam pencarian data.

4. Membuat aplikasi yang dapat menampilkan informasi secara lengkap dan laporan sehingga tidak terjadi kesalahan dalam pembuatan laporan.

\section{Algoritma Penyelesaian Masalah dengan Flowchart dan Pseudocode}

\section{Flowchart Pencarian Kopi}

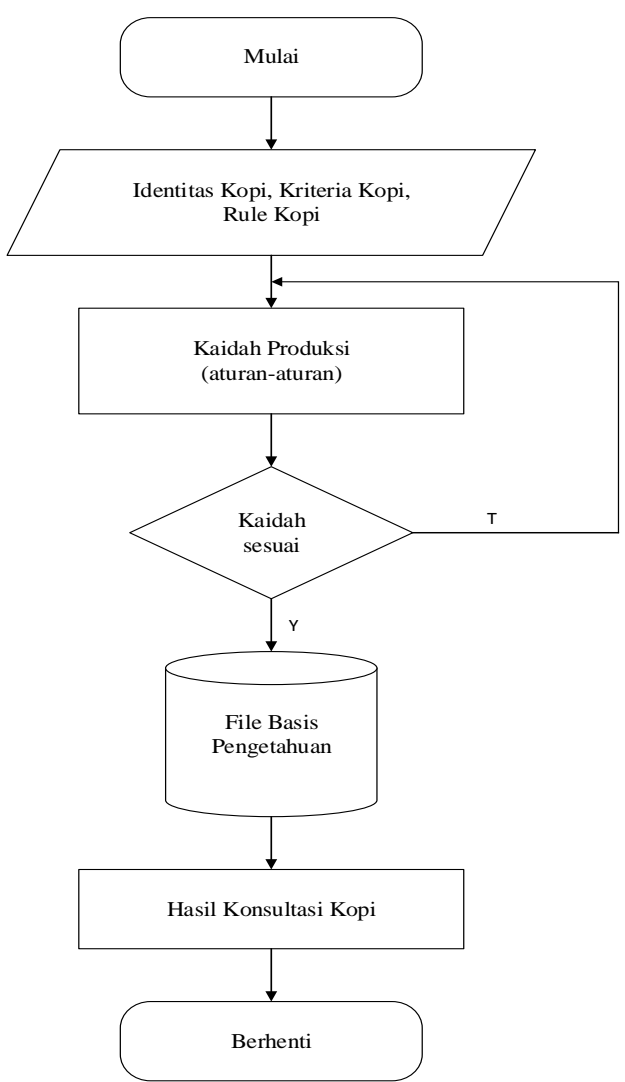

Gambar 1. Flowchart pencarian kopi 
Pseucode Pencarian Kopi

Tampilkan Menu Konsultasi Kopi

Pilih= "Input Form Kopi" Tampilkan Input Form Kopi

If jawab="Berhasil" then

Tampilkan Menu Data Form Kopi

Else

Kembali ke Menu Input Form Kopi

Pilih = "Identifikasi, Keriteria Kopi dan Rule Kopi" Tampilkan Menu

End if Identifikasi, Keriteria Kopi dan Rule Kopi

If jawab = "Berhasil" then then Tampilkan menu hasil konsultasi

Else

Kembali ke menu Identifikasi, Keriteria Kopi dan Rule Kopi

End if

End if

Rule fuzzy yang digunakan pada penelitian ini menggunakan pealatan bantu untuk menguji tanaman yang cocok terhadap keadaan tanah yang hendak dianalisa. Peraturan atau rule pada bentuk (IF-THEN). Berikut urutan dari rule yang akan dibentuk dari data kopi, bersumber dari [10].

2. Flowchart Menu Utama

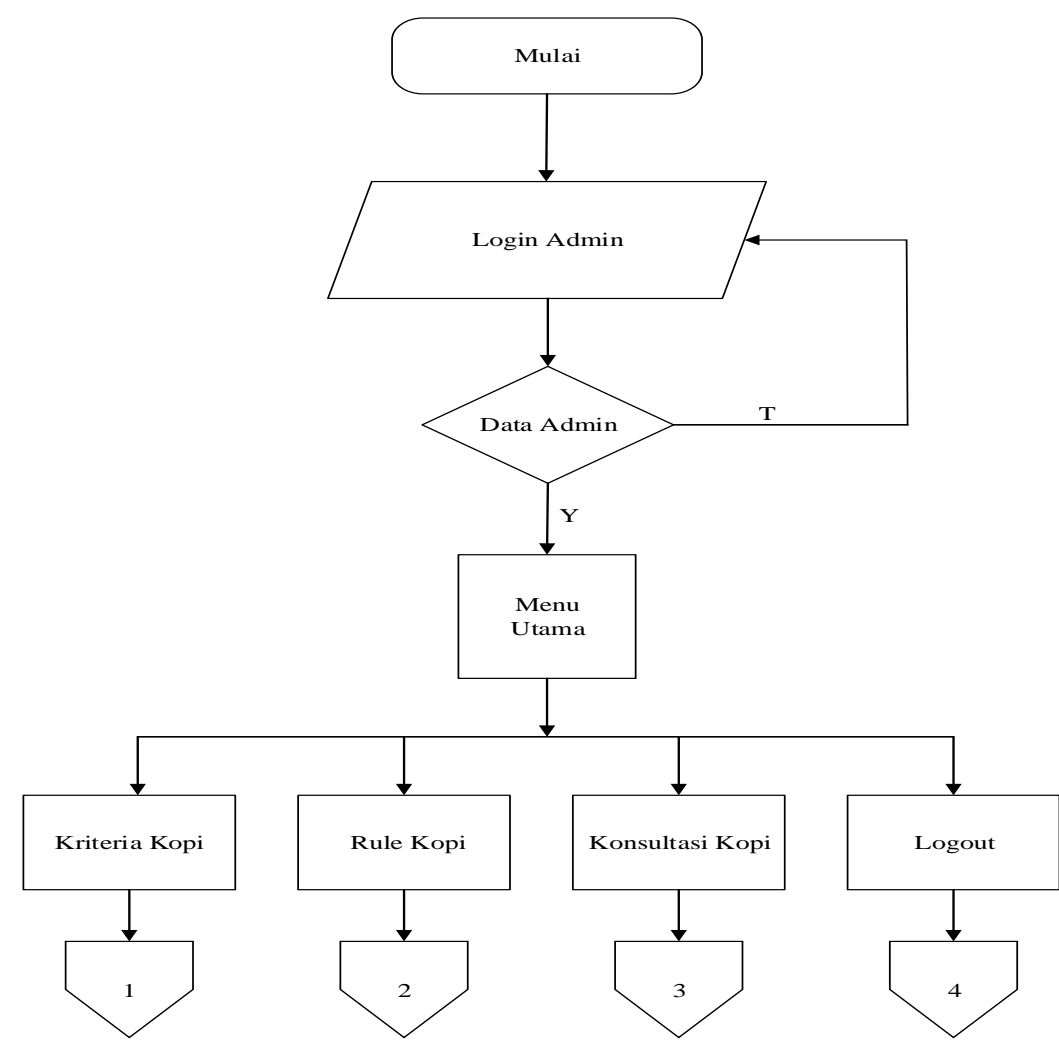

Gambar 2. Flowchart Menu Admin

Pseucode Menu Admin

Tampilkan Login Admin

Pilh= "Inputlogin" Tampilkan Menu Utama

If jawab= "Berhasil" then

Tampilkan Menu Utama

Else

Kembali ke Login Admin 
Do pilihan

Pilih="Home" Lakukan modul menu Home

Pilih ="Menu Kriteria" Lakukan modul menu Kriteria Kopi Pilih="Menu Rule "Lakukan modul menu Rule Kopi

End if

3. Flowchart Rule Kopi

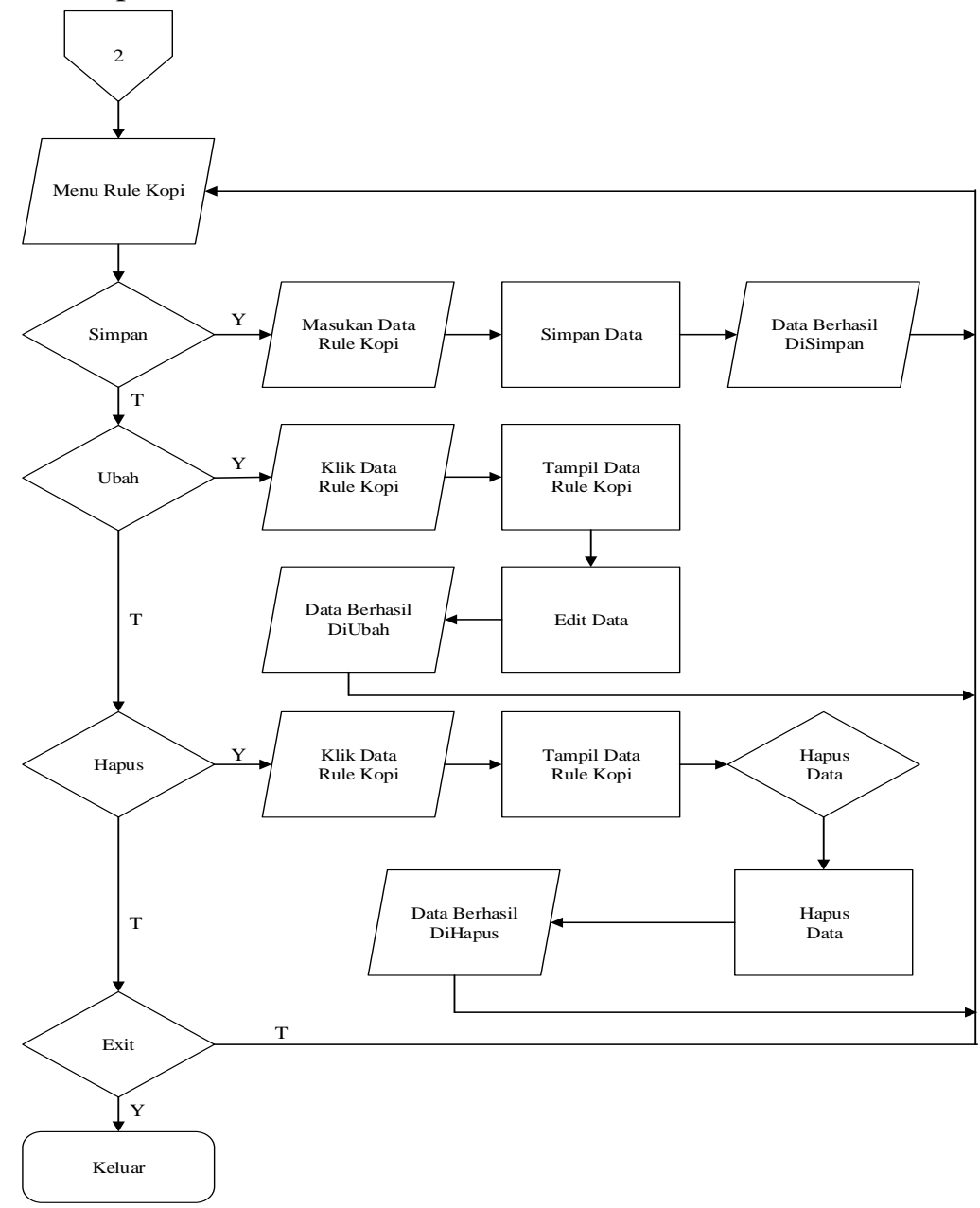

Gambar 3. Flowchart Rule Kopi

Pseucode Menu Rule Kopi

Input fakta kriteria kopi dari user

Masukan kriteria kedalam variable

Susun fakta berdasarkan variable

$X=$ Jumlah Goal Kopi

Kecocokan $=0$

Hitung kecocokan Rule pada tiap Goal kopi

For $(z=1, z<$ panjang_rule, $z++)$

Iffaktauser $=$ rule then kecocokan ++

Hasilrule []$=$ kecocokan

End for

Pilih Hasilrule[] yang mendekati Goal

If Hasilrule[] $\geq 1$ Then

Tampilkan Goal yang didapat.

Else

Goal tidak ditemukan. 


\section{Tampilan Layar}

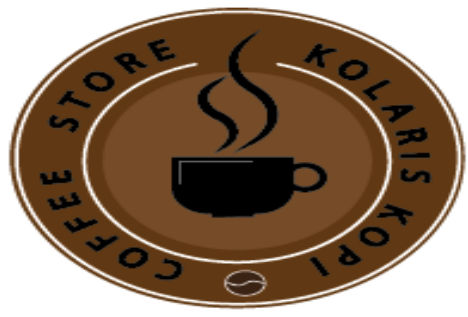

Username

Password

Gambar 4. Menu Login

Layar diatas menampilkan form login, masukan user dan password yang sudah dibuat dan klik login untuk menampilkan menu utama.

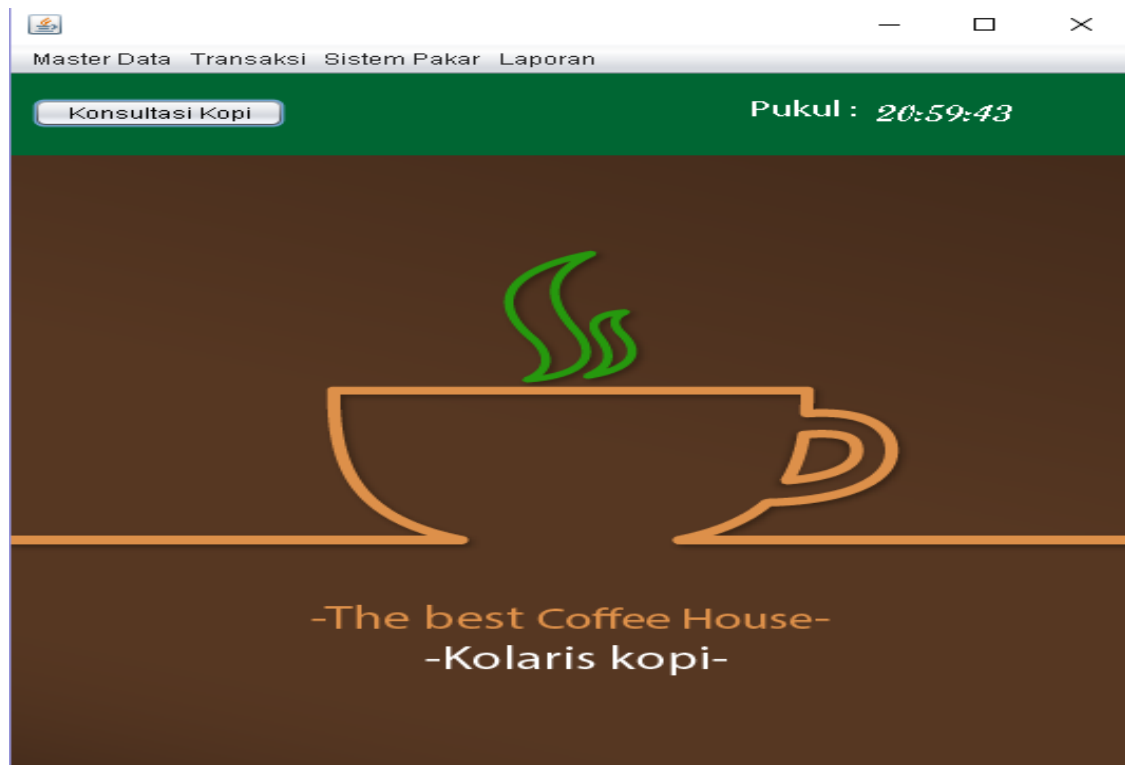

Gambar 5. Menu Utama

Pada tampilan menu utama terdapat menu bar yang di dalamnya terdapat beberapa menu item yaitu sistem pakar (Rule Kopi, Kriteria Kopi, Konsultasi Kopi) dan Laporan 


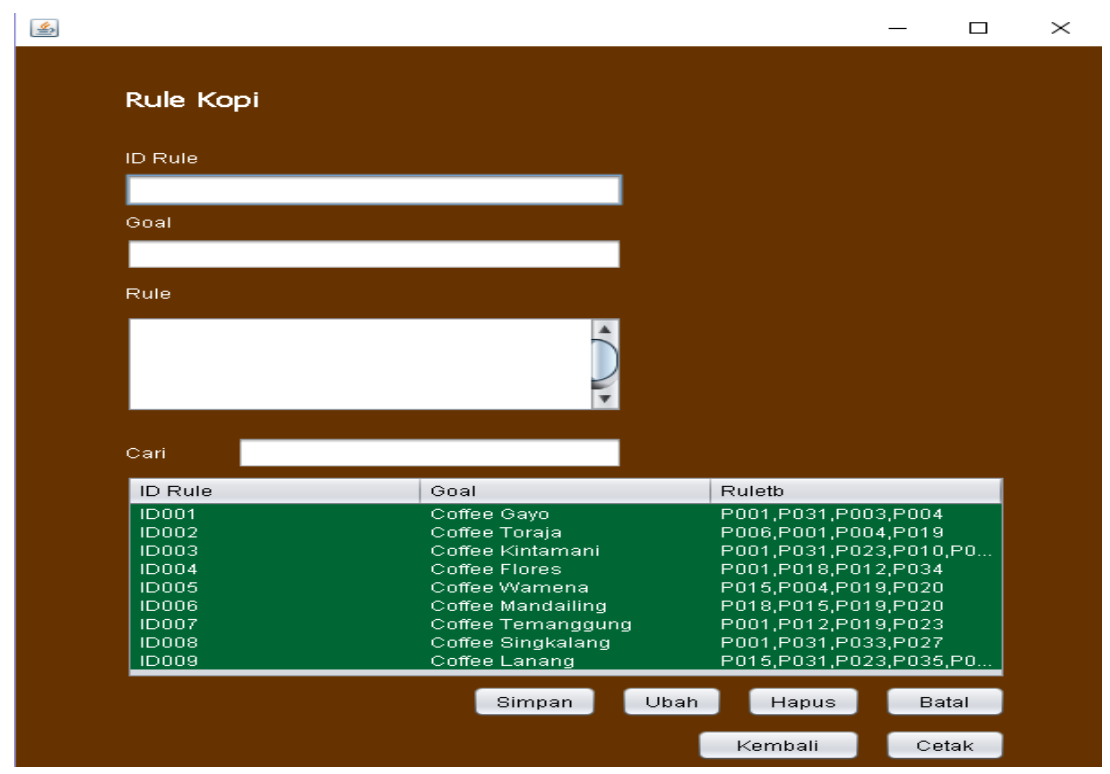

Gambar 6. Menu Rule Kopi

Pada tampilan menu rule kopi terdapat inputan untuk membuat data rule kopi yang baru, form ini digunakan untuk memasukan aturan-aturan pada setiap jenis kopi.

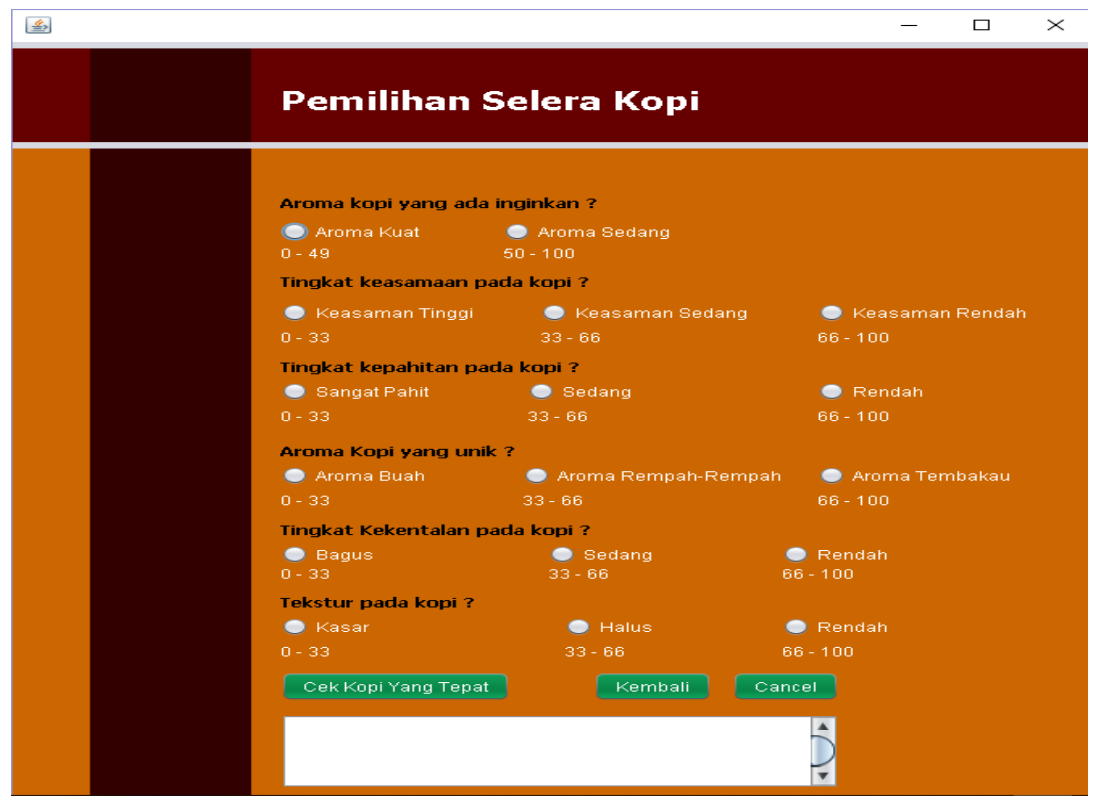

Gambar 7. Menu Konsultasi Kopi

Pada form menu konsultasi kopi berisikan beberapa pertanyaan yang berisi selera kopi, form ini ditujukan untuk konsumen dengan cara menjawab pertanyaan yang tersedia pada form apabila konsumen telah selesai memilih, selanjutnya klik button cek kopi yang tepat maka sistem akan otomatis menampilkan hasil kopi dari hasil menjawab pertanyaan pada form.

\section{SIMPULAN}

Sistem pakar Penentuan Kopi Terbaik Berdasarkan Barista yang dikembangkan merupakan aplikasi desktop yang memudahkan karyawan café dalam melakukan pendataan, melakukan transaksi, dan memudahkan konsumen menentukan kopi apa yang tepat sesuai selera. Dari hasil penelitian dapat disimpulkan beberapa hal sebagai berikut:

1. Program Sistem Pakar Penentuan Kopi Terbaik berbasis komputerisasi yang tepat dan akurat diharapkan memberikan alternatif bagi pengguna. 
2. Penggunaan database pada penyimpanan data agar menjadi lebih efektif.

3. Penggunaan metode Fuzzy Logic dalam melakukan perhitungan pengidentifikasian menu kopi yang tepat berhasil diterapkan sesuai analisa pakar.

\section{DAFTAR PUSTAKA}

[1] M. Soleh, "Sistem Pakar Penentuan Selera Konsumen Terhadap Menu Kopi Dengan Metode Fuzzy Logic," pp. 0-5, 2010.

[2] A. Kamsyakawuni, R. Gernowo, and E. A. Sarwoko, "Aplikasi Sistem Pakar untuk Diagnosa Penyakit Hipertiroid dengan Metode Inferensi Fuzzy Mamdani,” J. Sist. Inf. Bisnis, vol. 2, no. 2, pp. 58-66, 2012.

[3] N. Firmansyah, "Sistem Pakar Indentifikasi Pengecekan Kualitas Kupi Berbasis Web Dengan Menggunakan Metode Certainty Factor," J. Rekursif, vol. 5, no. 3, pp. 298-306, 2017.

[4] G. feri handono Mohammad yazdi, "Sistem pakar fuzzy penentuan kualitas kakao," Obstet. Gynaecol. Jpn., vol. 65, no. 10, p. N-250-"N-253", 2013.

[5] D. A. Rahmawati, "Penerapan Fuzzy Logic Dengan Menggunakan Metode Mamdani Untuk Memprediksi Kualitas Kopi," 2015.

[6] L. Lukman, "Aplikasi Sistem Pakar Untuk Diagnosa Penyakit Mata Menggunakan Php dan Mysql," Fakt. Exacta, vol. 11, no. 1, p. 47, 2018.

[7] Y. Liza Yulianti, "SISTEM INFORMASI PERSEDIAAN BARANG PADA PT . SURYA NUSA BHAKTINDO BENGKULU ABSTRACT One effort to present information about the construction material supply house, is one of them by making Materials Inventory application using Microsoft Visual Basic 6 .," vol. 8, no. 1, 2012.

[8] M. Rosaliza, "Wawancara, sebuah interaksi komunikasi dalam penelitian kualitif." 2015.

[9] N. Nilamsari, "Memahami studi dokumen dalam penelitian kualitatif," vol. XIII, no. 2, pp. 177-181, 2014.

[10] I. Zulfa, R. Septima, and I. Syah, "Sistem Pakar Untuk Mengetahui Tingkat Kesuburan Tanah Pada Jenis Tanaman Kopi Menggunakan Metode Fuzzy Logic ( Studi Kasus Kota Takengon ),” vol. 5, no. 36, pp. 37-52, 2020. 